\title{
Developing Tsunami fragility curves using remote sensing and survey data of the 2010 Chilean Tsunami in Dichato
}

\author{
E. Mas ${ }^{1}$, S. Koshimura ${ }^{2}$, A. Suppasri ${ }^{3}$, M. Matsuoka ${ }^{4}$, M. Matsuyama ${ }^{5}$, T. Yoshii ${ }^{6}$, C. Jimenez ${ }^{7}$, F. Yamazaki ${ }^{8}$, and \\ F. Imamura ${ }^{1}$ \\ ${ }^{1}$ International Research Institute of Disaster Science (IRIDeS), Tsunami Engineering Laboratory, Tohoku University, Japan \\ ${ }^{2}$ IRIDeS, Laboratory of Remote Sensing and Geoinformatics for Disaster Management, Tohoku University, Japan \\ ${ }^{3}$ IRIDeS, Earthquake induced Tsunami Risk Evaluation (Tokio Marine), Tohoku University, Japan \\ ${ }^{4}$ Geoinformation Center, Geological Survey of Japan, National Institute of Advanced Industrial Science and Technology, \\ Japan \\ ${ }^{5}$ Civil Engineering Laboratory, Central Research Institute of Electric Power Industry, Japan \\ ${ }^{6}$ Environmental Science Research Laboratory, Central Research Institute of Electric Power Industry, Japan \\ ${ }^{7}$ Universidad Nacional Mayor de San Marcos, FENLAB, Peru \\ ${ }^{8}$ Department of Urban Environment Systems, Graduate School of Engineering, Chiba University, Japan
}

Correspondence to: E. Mas (erick@tsunami2.civil.tohoku.ac.jp)

Received: 8 February 2012 - Revised: 27 June 2012 - Accepted: 10 July 2012 - Published: 24 August 2012

\begin{abstract}
On 27 February 2010, a megathrust earthquake of $M_{\mathrm{w}}=8.8$ generated a destructive tsunami in Chile. It struck not only Chilean coast but propagated all the way to Japan. After the event occurred, the post-tsunami survey team was assembled, funded by the Japan Science and Technology Agency (JST), to survey the area severely affected by the tsunami. The tsunami damaged and destroyed numerous houses, especially in the town of Dichato. In order to estimate the structural fragility against tsunami hazard in this area, tsunami fragility curves were developed. Surveyed data of inundation depth and visual inspection of satellite images of Dichato were used to classify the damage to housing. A practical method suitable when there are limitations on available data for numerical simulation or damage evaluation from surveys is presented here. This study is the first application of tsunami fragility curves on the South American Pacific coast and it might be of practical use for communities with similar characteristics along the west Pacific coast. The proposed curve suggests that structures in Dichato will be severely damaged - with a $68 \%$ probability - already at $2 \mathrm{~m}$ tsunami inundation depth.
\end{abstract}

\section{Introduction}

The largest earthquake in history was the 1960 Chile earthquake and tsunami. Following the north edge of this rupture area, on 27 February 2010 a megathrust earthquake of $M_{\mathrm{w}}=8.8$ occurred. The earthquake generated a destructive tsunami in Chile and the whole Pacific. It is the third largest earthquake in the 21 st century and eighth in the recorded history; it is also known as the Maule Earthquake. The ruptured area was of nearly $450 \mathrm{~km}$, extending from southern Santiago in the north to the Arauco Peninsula in the southern area of the city of Concepción. This earthquake was an inter-plate mega-subduction event with a pure reverse mechanism (Pulido et al., 2010). The earthquake triggered a tsunami, and around thirty minutes after the first shock, several waves hit the coast. After the event occurred, the post-tsunami survey team was assembled, funded by the Japan Science and Technology Agency (JST), to survey the area severely affected by the tsunami. The tsunami damaged and destroyed numerous houses, especially in the town of Dichato. As in previous events, in order to estimate the structural fragility against tsunami hazard in the area, tsunami fragility curves were developed. Tsunami fragility is a new measure for the estimation of structural damage and fatalities due to tsunami by integrating satellite remote sensing, 


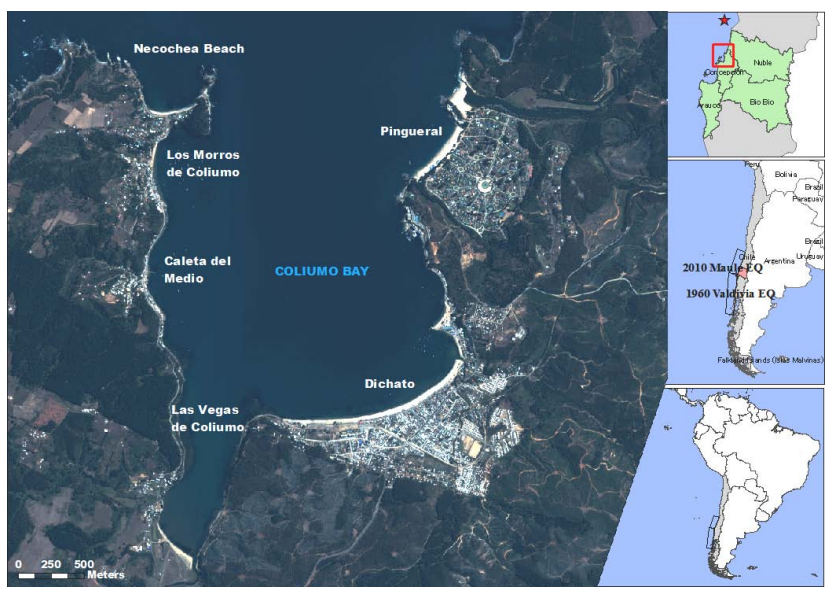

Fig. 1. Dichato is located in the Coliumo Bay of the Bío Bío region in Chile, around $80 \mathrm{~km}$ south of the epicenter.

field survey, numerical modeling, and historical data analysis with the geographic information system (GIS) (Koshimura et al., 2009b). The term "tsunami fragility" was introduced by Koshimura et al. (2009b), and so was its determination by numerical method (Koshimura and Yanagisawa, 2007; Koshimura et al., 2009a). A fragility curve is developed here for the area of Dichato in Chile. This town was reported to be affected on more than $80 \%$ of its built-up area (Yamazaki et al., 2010). A brief report of the post-tsunami survey and damages to Dichato is presented. This paper describes several methodologies for developing tsunami fragility curves, including the method applied in the case of Dichato. Damage interpretation using remote sensing and satellite images is explained. Then, the main calculation and the proposed fragility curve are shown. Finally, we make a comparison and discussion of previous tsunami fragility curves developed in other areas.

\section{Post-tsunami field survey}

\subsection{Dichato}

Dichato is one of the largest towns in Coliumo Bay, located at the south end of the bay (Fig. 1). It belongs to the municipality of Tomé and holds approximately 3000 inhabitants. Dichato was a very popular beach area, and in the past also a camping area suitable for water sports and recreation. It was reported that more than $80 \%$ of the built-up area suffered from the tsunami.

\subsubsection{Damages}

The tsunami arrived in this area around one hour after the earthquake. Most of the resident population was already evacuated to nearby highland areas, however tourists and some elders underestimated the sea because of their

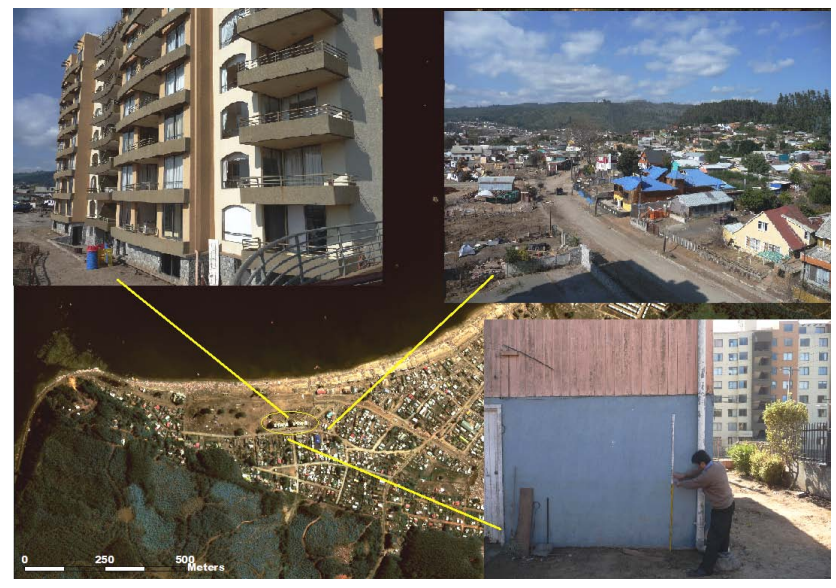

Fig. 2. Location of the ten-story apartment buildings and surrounding houses.

lack of knowledge or previous experience of 1960 Chile tsunami, when almost no damage occurred in this area. The numbers of fatalities and missing persons were reported as 66 persons. According to the Dichato-Tomé emergency office, 405 families were living in camps still after one month from the earthquake. A total of 1223 families were affected on their properties (Koshimura et al., 2011). The tsunami penetrated as far as $800 \mathrm{~m}$, and in some areas of Coliumo Bay, measures were of approximately $2.2 \mathrm{~km}$ inundation and an estimated maximum water depth of $6 \mathrm{~m}$ in the town (Bray and Frost, 2010). According to witnesses, the first wave arrived within an hour after the earthquake, followed by a second and third set of waves in the next five hours. The most destructive wave was the second or third wave, depending on the location in the bay. The characteristics of houses in Dichato were mixed, some made of masonry in the first floor and wooden in the second floor, others of lightweight material such as wood and corrugated metal. Only two ten-story buildings on the west side of the town and no more than $150 \mathrm{~m}$ from the shoreline are reinforced concrete and engineered apartment buildings (Fig. 2). There were no structural damages despite that the first floor and the basement were inundated and submerged under waves of around $3 \mathrm{~m}$ height. Also behind these buildings several houses starting a short slope to the hill were apparently protected from the wave force by these two buildings and the slope.

\section{Developing tsunami fragility curves}

According to Koshimura et al. (2009a), "tsunami fragility" was introduced as a new measure for the estimation of tsunami damage to buildings. The probability of structural damage is estimated from the hydrodynamic features of tsunamis. Velocity, hydrodynamic force, inundation flow and inundation depth are some of the parameters used by previous research studies to express the tsunami fragility 
or fatality ratio. Tsunami fragility curves have been developed so far in response to the Indian Ocean tsunami of 2004 (Koshimura and Yanagisawa, 2007; Suppasri et al., 2011; Murao and Nakazato, 2010), the Samoan tsunami of 2009 (Gokon et al., 2011), the historic tsunami caused by the 1993 Hokkaido Nansei-oki earthquake in Okushiri, Japan (Koshimura and Kayaba, 2010; Suppasri et al., 2012a), and recently after the 2011 Great East Japan Earthquake (Suppasri et al., 2012b). However, architecture and engineering of these countries are of different characteristics from the ones applied in the southwestern Pacific coast. From the field survey of the great event of 2010 in Chile and the damage recognition through satellite images, a first proposal of a tsunami fragility curve for a high risk area such as the peruvian and chilean coasts is presented here. Three methods are originally described by Koshimura et al. (2009a) and Suppasri et al. (2011). In this study we briefly describe the three original methods plus a fourth approach resulting from the practical combination of the last two methods.

\subsection{Tsunami fragility from historical data}

Koshimura et al. (2009a) developed tsunami fragility curves based on the historical data and records of building damage in Japan. Japan is one of the nations with a long history of event records, especially in the case of tsunamis. The data used by Koshimura et al. (2009a) included post-tsunami surveys, documents and reports of tsunami height and inundation depths for the 1896 Meiji-Sanriku, 1933 Showa-Sanriku, and 1960 Chile tsunamis. There are several approaches for damage classification according to the quality of data available. The structural damage classification used for this case in the Okushiri Island was: washed away, completely destroyed, moderately damaged, and only flooded.

\subsection{Tsunami fragility determined from satellite remote sensing and numerical modeling}

High-resolution satellite imagery is used for damage detection through visual interpretation and classification. Then, the numerical simulation of the tsunami, using highresolution bathymetry and topography data, is used as the method to obtain the hydrodynamic features of the tsunami. The combination of these two steps defines the relationship between damage probability and characteristics of tsunami inundation. Due to difficulties in the accurate interpretation of damage during the visual inspection of roof condition, a limitation on the damage classification is observed in this method. Thus, the classification of structural damage is limited to two levels, the washed away or collapsed level and the no damage or survived condition.

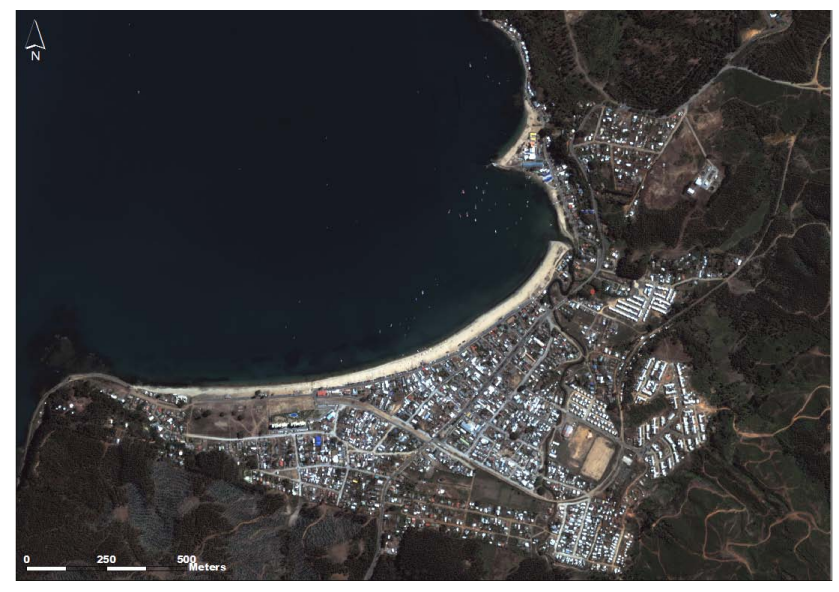

Fig. 3. Satellite image taken before the tsunami event in Dichato (Chile) - 10 February 2010.

\subsection{Tsunami fragility determined from damage inspection during field surveys}

A survey database (Foytong, 2007; Ruangrassamee et al., 2006) is used to construct fragility curves. The levels for structural damage classification can be more specific in this case. Classification according to the damage observed in structural members of the building is possible, instead of an overall interpretation of the damage. For instance, Foytong (2007) and Ruangrassamee et al. (2006) also evaluated the effects of tsunamis on buildings categorized according to the number of stories. Their findings showed a strong relationship between fragility curves and the capacity of buildings related to the number of stories.

\subsection{Tsunami fragility determined from satellite remote sensing and field surveys}

As a combination of the last two methods described above, this approach can be conducted when:

- the field survey data do not include building damage inspection, or

- the available data for numerical modeling are not of high-resolution accuracy.

For this case, the data of several points of inundation depth measured during the field survey are interpolated using geographic information system (GIS) tools. The building damage classification is considered in two levels, the washed away or collapsed level and the survived or non-damaged condition. The resulting interpolated surface is combined with the damage interpretation to define the relationship between inundation depth and damage probability. 


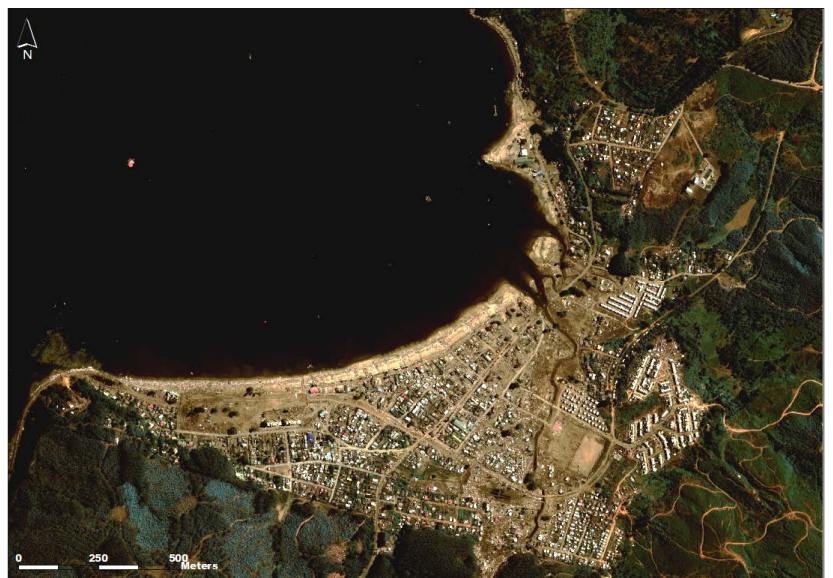

Fig. 4. Satellite image taken after the tsunami event in Dichato (Chile) - 10 March 2010.

\section{Developing Tsunami fragility curves for Dichato}

\subsection{Collecting data and damage interpretation}

Remote sensing is used for the classification of tsunami damage by taking advantage of satellite images. The advantage of using satellite images for damage interpretation is the capability of understanding structural damage visually. Satellite images taken before - QuickBird - and after - WorldView-2 - the tsunami event were used for the visual damage inspection. The pre-event image (Fig. 3) was acquired on 10 February 2010, while the post-event image (Fig. 4) corresponds to 10 March 2010. The spatial resolutions of the pre-event image and post-event image are $0.6 \times 0.6 \mathrm{~m}^{2}$ and $2.0 \times 2.0 \mathrm{~m}^{2}$, respectively. Higher resolution for a post-event image allows a finer interpretation. For instance, Gokon et al. (2011) used four damage levels, "not collapsed", "major damage", "collapsed" and "washed away" and a post-image of $0.6 \times 0.6 \mathrm{~m}^{2}$ to construct fragility curves. In our case, the resolution of the available image of Dichato is not as fine as the images used by Gokon et al. (2011) in such a visual interpretation. Then we followed the approach taken by Suppasri et al. (2011), who analyzed an IKONOS satellite image of $1.0 \times 1.0 \mathrm{~m}^{2}$ resolution into two levels of classification. Thus, in this study the damage classification was limited to the structural destruction or failure by the interpretation of roof condition or drifted structures without considering the impact of debris. Classification labels are "washed away" and "survived". Due to the limitations of the visual inspection from satellite images, some "survived" structures may have some level of damage that was not possible to identify through the remote sensing technique.

As a first step of the method to develop fragility curves, polygons of structures are created over the pre-event image. Also inundation depth and the run-up limit line obtained
Table 1. Comparison of interpolation methods.

\begin{tabular}{lccc}
\hline Method & Min. Value & Max. Value & $R^{2}$ \\
\hline Kriging & 0.000 & 4.762 & 0.848 \\
Natural Neighbor & 0.000 & 5.410 & 0.911 \\
Spline & -10.704 & 28.592 & 0.809 \\
\hline
\end{tabular}

from field survey are drawn to confine the interpretation to the affected area (Fig. 5a, b). Next, a visual interpretation of damage is conducted using the post-event image; each polygon is classified either as "washed away" (red) or "survived" (blue) by simple comparison of pre- and post-event images (Fig. 5c). Finally, inundation depth point data and points of inundated area boundaries are merged and interpolated (Fig. 5d). Among the popular and available methods of interpolation, we explored three common methods: Kriging, Natural Neighbor and Spline. Next, we selected the one with the highest correlation to the surveyed data as the most suitable for the fragility curve estimation. A total of 81 points, 56 within the inundation area and 21 in the inundation limit, were interpolated using the three methods mentioned above (Fig. 6).

Results of the correlation of interpolated values at the location of the survey data versus the measured inundation depth are shown in Fig. 7 and Table 1. Also minimum values and maximum values in the interpolation method were used as an indicator to reject the applicability of the method. In general, the appearance of non-real values - negative inundation depth or very large depth values compared to the surveyed maximum depth - is considered as the criterion for rejection. Therefore, from Table 1, the Spline method is rejected due to the negative and extremely large value estimations, despite the good correlation in the location of survey points. On the other hand, Kriging and Natural Neighbor methods seem to be appropriate for the further estimation of fragility curves. However, it is important to consider that the maximum value of the interpolation should be close to the maximum inundation depth found during the survey. In Dichato, we found that the maximum height of the tsunami was estimated at six meters. Thus, Natural Neighbor method gives a higher maximum value close to the maximum inundation depth of the survey and also the best correlation with survey data points. It is worth noticing that not always this method will give the best correlation and values; it is important to compare different interpolation methods in order to use the best of them. This is because future surveys in other locations will show different spatial distributions of depths from the one explored here.

Finally, in this study the Natural Neighbor method of interpolation was selected as the suitable technique for the estimation of the fragility curve. The limitation of this method is bound by the available survey data points and its spatial distribution with respect to the inundation limit. That is, if 

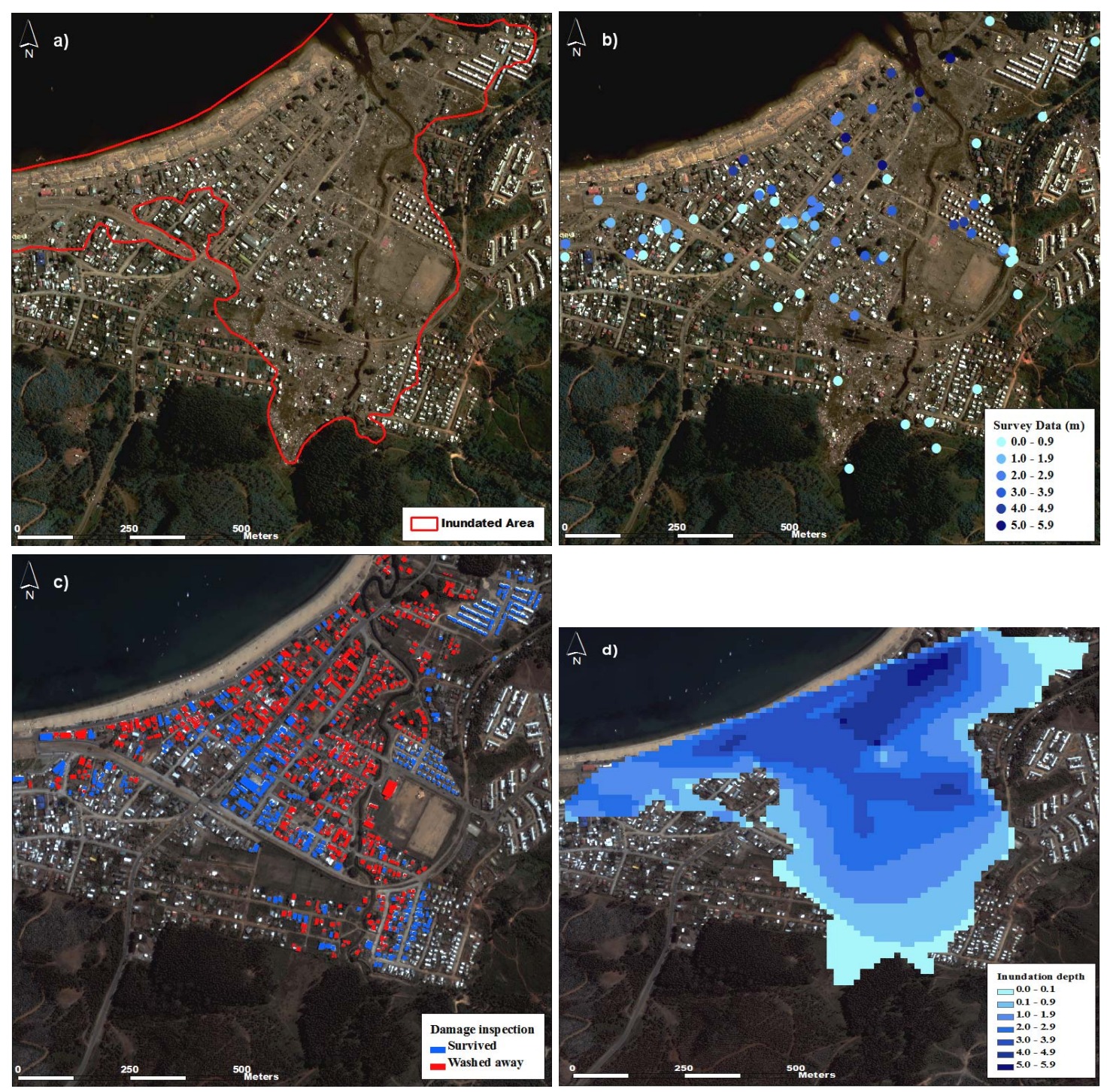

Fig. 5. (a) The line shows the maximum limit of tsunami inundation in Dichato. (b) The points show the locations and inundation depth values estimated during the field survey. (c) The polygons show the result of the damage visual inspection based on the comparison of preand post-event images. Damage classification is either "survived" or "washed away". (d) The surface shows the result of the interpolation of the survey data within the inundated area.

no points were surveyed around a damaged area, the interpolation might give an underestimation of inundation depth in the area. For example, it is observed in Fig. 5b that the survey data around the southeast area of Dichato are not as fine as near to the shoreline. Then, although in the damage inspection we found certain "survived" and "washed away" classifications (Fig. 5c), the interpolation method does not allow to observe significant inundation depths near the runup zone due to the lack of survey points (Fig. 5d). Therefore, the analysis of the fragility curve is constructed for structures subject to more than $0.10 \mathrm{~m}$ of inundation depth, avoiding structures near the high uncertainty area.

\subsection{Fragility curves}

From the visual inspection of 915 buildings based on the damage classification described, a histogram of tsunami inundation depth and the number of washed-away buildings was plotted (Fig. 8). The inundation depth in the histogram plot is determined by taking the median value within a range that includes approximately 50 structures. Then, the relationship of damage probability and inundation depth is explored through a linear regression analysis. 

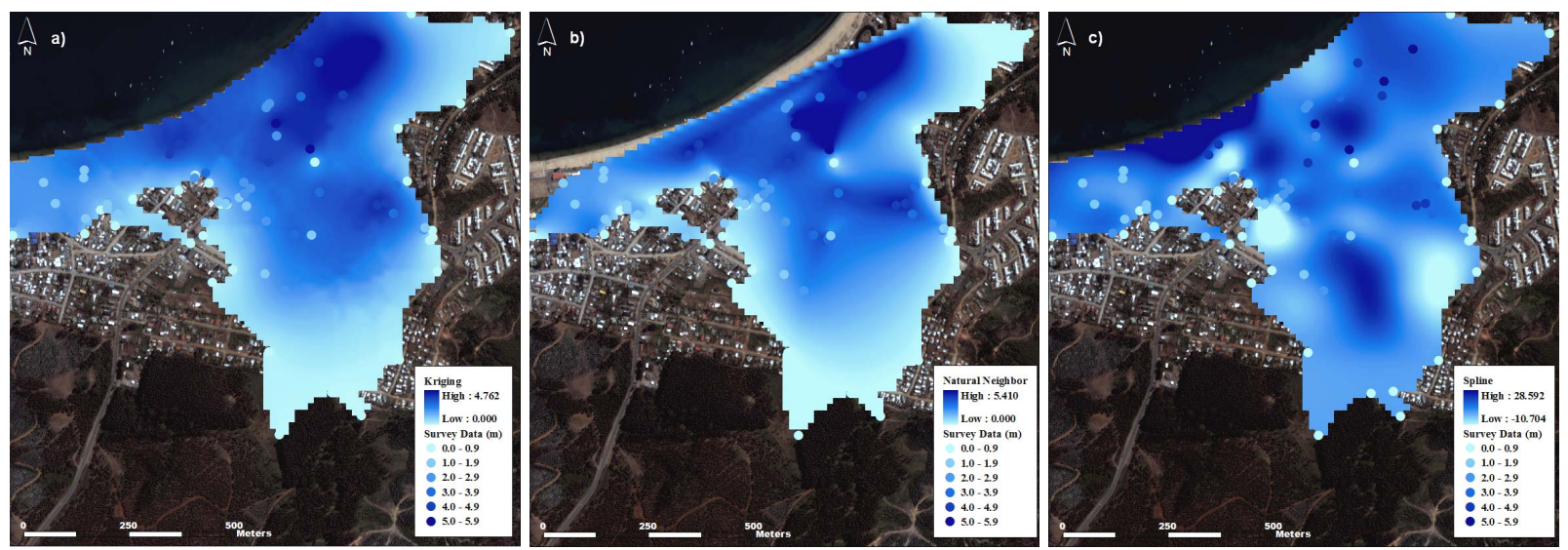

Fig. 6. Three interpolation methods for the point survey data were used. (a) Kriging method; (b) Natural Neighbor method; (c) Spline method.
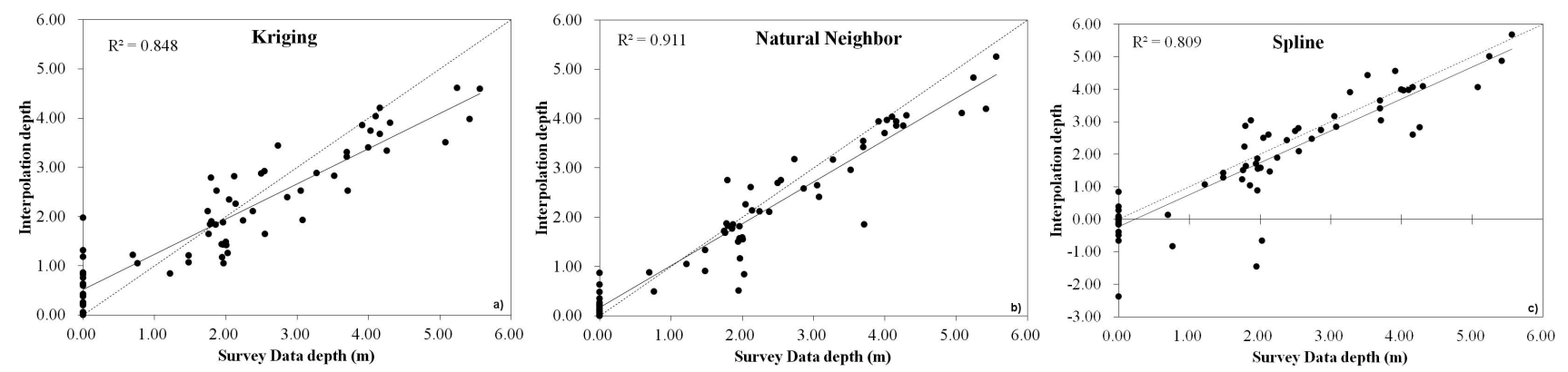

Fig. 7. Correlation of inundation depth from survey data points and interpolation methods. The Natural Neighbor method shows the best correlation with the real data.

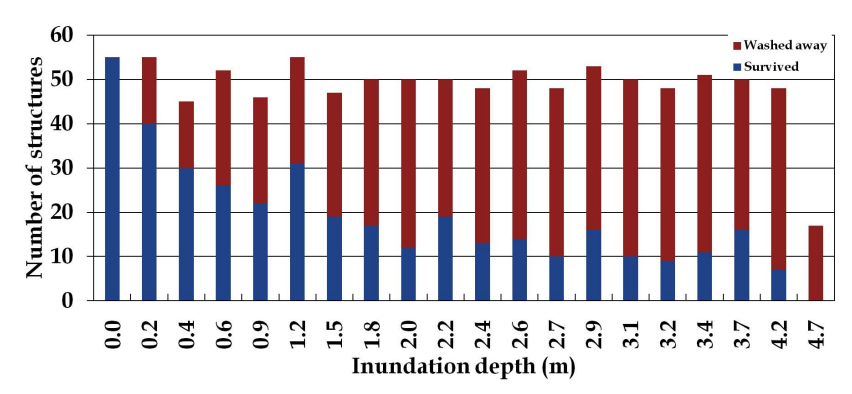

Fig. 8. Histogram of the numbers of washed-away and survived structures in terms of inundation depth range within the tsunami inundation zone. Each inundation depth range is determined by exploring a range that includes approximately 50 structures.

The cumulative probability $P$ of occurrence of damage is given by Eq. (1):

$\mathrm{P}(x)=\Phi\left[\frac{\ln (x)-\mu^{\prime}}{\sigma^{\prime}}\right]$.

In this equation, $\Phi$ represents the standardized lognormal distribution function, $x$ stands for the tsunami inundation depth, and $\mu^{\prime}$ and $\sigma^{\prime}$ are the mean and standard deviations of $\ln (x)$, respectively. The two statistical parameters of a fragility curve, $\mu^{\prime}$ and $\sigma^{\prime}$, are obtained by plotting $\ln (x)$ against the inverse of $\Phi$ on lognormal probability papers, and performing least-squares fitting of this plot. Finally, two parameters are obtained by taking the intercept $\left(=\mu^{\prime}\right)$ and the angular coefficient $\left(=\sigma^{\prime}\right)$ in Eq. (2):

$\ln (x)=\sigma^{\prime} \Phi^{-1}+\mu^{\prime}$.

Parameters are determined throughout the regression analysis to obtain the best fit of a fragility curve for the inspected structures with respect to the inundation depth (Table 2 and Fig. 9f).

\section{Discussion}

Previous tsunami damage interpretations and fragility curves developed for Japan, Indonesia, Thailand and the American Samoa are summarized and compared to the recently developed fragility curve for Chile (Table 2). In the case of the damage probability estimation for Japan, Thailand and Indonesia, fragility curves were developed using numerical simulations of the tsunamis. Through this mean, several features of a tsunami can be used in the statistical approach explained before. Then, it is possible to obtain damage 
Table 2. Summary of statistical parameters for developed fragility curves (modified from Suppasri et al., 2012a). The parameters $\mu$ and $\sigma$ are the mean and standard deviations of the normal distribution, while $\mu^{\prime}$ and $\sigma^{\prime}$ are similar parameters in a standardized lognormal distribution.

\begin{tabular}{|c|c|c|c|c|c|c|c|c|c|c|c|}
\hline Event (Year) & Location & Country & Structure type & $\begin{array}{c}\text { No. of } \\
\text { structures } \\
\text { inspected }\end{array}$ & $\begin{array}{l}\text { No. of } \\
\text { structures in } \\
\text { range }\end{array}$ & $\mu$ & $\sigma$ & $\mu^{\prime}$ & $\sigma^{\prime}$ & $R^{2}$ & $\begin{array}{l}\text { Fragility curve } \\
\text { (Fig. 9) }\end{array}$ \\
\hline Nansei Hokkaido (1993) & Okushiri Is. - Aonae & Japan & Wood & 523 & 50 & - & - & 0.216 & 0.736 & 0.82 & a. \\
\hline Indian Ocean (2004) & Banda Aceh & Indonesia & $\begin{array}{l}\text { Wood, timber, } \\
\text { RC }\end{array}$ & 48910 & 1.000 & 2.985 & 1.117 & - & - & 0.99 & b. \\
\hline Indian Ocean (2004) & Phang Nga & Thailand & $\begin{array}{c}\text { Reinforced } \\
\text { Concrete (RC) }\end{array}$ & 3.007 & 100 & - & - & 0.689 & 0.903 & 0.80 & c. \\
\hline Indian Ocean (2004) & Phuket & Thailand & $\mathrm{RC}$ & 1.589 & 50 & - & - & 0.917 & 0.642 & 0.62 & d. \\
\hline Samoa (2009) & American Samoa & USA & $\begin{array}{c}\mathrm{RC} \\
\text { Wood, }\end{array}$ & 344 & 20 & - & - & 1.170 & 0.691 & 0.89 & e. \\
\hline Chile (2010) & Dichato & Chile & $\begin{array}{l}\text { Masonry, } \\
\text { mixed }\end{array}$ & 915 & 50 & - & - & 0.092 & 1.272 & 0.86 & f. \\
\hline
\end{tabular}
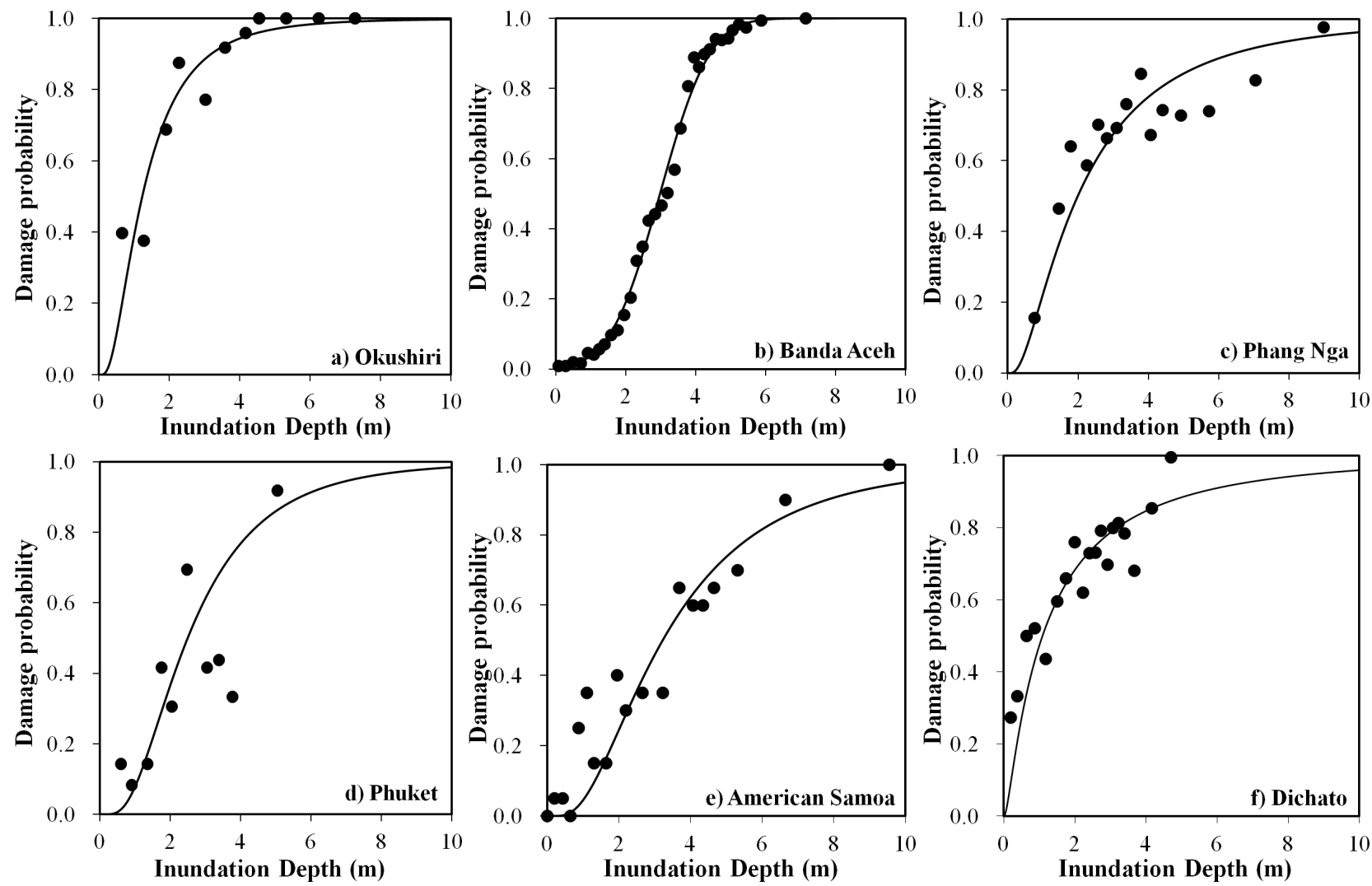

Fig. 9. Tsunami fragility curves for structural destruction probability previously developed for other locations on the globe. (a) Japan; (b) Indonesia; (c), (d) Thailand; (e) American Samoa - USA; (f) Chile.

probability functions related not only to the inundation depth but also the velocity and hydrodynamic force of the tsunami. In this paper, due to the nature of the available data from the field survey, only inundation depth has been used. Thus, for the comparative analysis of fragility curves, we will use the ones related to the inundation depth. A two-meter $(2 \mathrm{~m})$ inundation depth is taken as a reference level for comparison among the existing and the proposed tsunami fragility curves. In the case of Chile - Dichato (Fig. 9f), the $2 \mathrm{~m}$ inundation depth estimates around $68 \%$ probability of damages in buildings of the area. A similar estimation is observed for Okushiri
- Aonae (Fig. 9a). It is worth to mention that a large number of structures in these samples were of wooden material. On the other hand, reinforced concrete (RC) structures around Indonesia, Thailand and the American Samoa (Fig. 9b, c, d, e) show lower damage probabilities estimated on $20 \%$ to $40 \%$. There is a rapid increase of damage probability in the first two meters of depth (0-2 m) in Dichato and Okushiri. This is due to the structure type of wooden and lightweight materials inspected, which have a short time resistance to the tsunami hydrodynamic flow. Not so steep and more skewed curves like the ones from Indonesia and the American Samoa 
show a comparatively higher strength of reinforced concrete buildings against tsunami characteristics. Fragility curves developed so far by several authors have been estimated using the same statistical approach. However, due to the nature of the available data, different methods were applied. In this study, we presented a practical method to overcome limitations observed in areas without damage evaluation data from field surveys or topographic and bathymetric data for numerical simulation.

\section{Conclusions}

Tsunami fragility is implemented for an assessment of structural damage within the exposed area from potential tsunami hazard scenarios. Using inundation depth from the posttsunami field survey data of the 27 February 2010 Chile earthquake, and through the inspection of damage using satellite imagery of the pre- and post-event in Dichato, tsunami fragility curves were constructed for the first time in a southwestern Pacific country. Two-level classification of structural damage was used here - "survived" and "washed away" - higher resolution of satellite images or damage evaluation in situ may improve the results presented here. The methodology applied in this paper overcomes data limitation of higher-resolution satellite imagery and high accuracy of bathymetry and topography data for the application of numerical models. A comparison of three interpolation methods was presented and the Natural Neighbor resulted in the best approximation to the survey data and the overall damage evaluation. In future applications of this method to other areas, it is possible that a different interpolation technique may give better results based on the spatial distribution of survey data. The fragility curve expresses the damage probability of structures in terms of inundation depth of a tsunami. This function of fragility can be used as a measure to assess the damage due to potential tsunamis. Multiplying the number of exposed structures by the damage probability from the fragility curves equivalent to the estimated tsunami hazard provides the quantitative estimation of tsunami damage. The fragility curve developed for the town of Dichato shows a high damage probability of $68 \%$ at a relatively low inundation depth of $2 \mathrm{~m}$. Application of this fragility curve in other areas should be carefully evaluated considering the uncertainties of local tsunami and structure characteristics that might be different from the ones inspected here.

Acknowledgements. This research was sponsored by Japan Science and Technology Agency (JST) through the project of Science and Technology Research Partnership for Sustainable Development (SATREPS-PERU). The authors acknowledge the support from the Japan Ministry of Education, Culture, Sports, Science and Technology (MEXT). Also, we express our deep appreciation to the Willis Research Network (WRN) under the Pan-Asian/Oceanian tsunami risk modeling and mapping project and the Tokio Marine \& Nichido Fire Insurance Co., Ltd. through the International Research Institute of Disaster Science (IRIDeS) at Tohoku University.

Edited by: S. Tinti

Reviewed by: two anonymous referees

\section{References}

Bray, J. and Frost, D.: Geo-engineering Reconnaissance of the 2010 Maule, Chile Earthquake, Tech. rep., Report of the NSF Sponsored GEER Associaton Team, http://www.geerassociation.org/GEER_PostEQReports/

Maule_Chile_2010/Ver2_Cover_Chile_2010.html, 2010.

Foytong, P.: Fragility of buildings damaged in the 26 December 2004 tsunami, Master thesis, Chulalongkorn University, 2007.

Gokon, H., Koshimura, S., Matsuoka, M., and Namegaya, Y.: Developing tsunami fragility curves due to the 2009 tsunami disaster in American Samoa, in: Proc. Coast. Eng. Conference (JSCE), Morioka, Japan, 2011.

Koshimura, S. and Kayaba, S.: Tsunami fragility inferred from the 1993 Hokkaido Nansei-oki earthquake tsunami disaster, J. Japan Assoc. Earthq. Eng., 10, 87-101, 2010.

Koshimura, S. and Yanagisawa, H.: Developing fragility curves for tsunami damage estimation using numerical model and satellite imagery, in: Proceedings of the 5th International Workshop on Remote Sensing for Disaster Response, Washington, USA, 2007.

Koshimura, S., Namegaya, Y., and Yanagisawa, H.: Tsunami Fragility A New Measure to Identify Tsunami Damage, J. Disaster Res., 4, 479-488, 2009a.

Koshimura, S., Oie, T., Yanagisawa, H., and Imamura, F.: Developing Fragility Functions for Tsunami Damage Estimation using Numerical Model and Post-Tsunami Data from Banda Aceh, Indonesia, Coast. Eng. J., 51, 243-273, doi:10.1142/S0578563409002004, 2009b.

Koshimura, S., Matsuoka, M., Matsuyama, M., Yoshii, T., Mas, E., Jimenez, C., and Yamazaki, F.: Field Survey of the 2010 Tsunami in Chile, in: 8th International Conference on Urban Earthquake Engineering, April 2010, 1-13, http://ares.tu.chiba-u.jp/ papers/ paper/2011/2011CUEE_Koshimura.pdf, 2011.

Murao, O. and Nakazato, H.: Vulnerability functions for Building based on Damage Survey Data in Sri Lanka after the 2004 Indian Ocean Tsunami, in: International Conference on Sustainable Built Environment (ICSBE-2010), December, 371-378, Kandy, Sri Lanka, 2010.

Pulido, N., Yagi, Y., Nishimura, N., and Kumagai, H.: Source rupture process and strong motion simulation of the Mw8.8, 2010 Chile Mega earthquake, in: Abstr. Fall meeting Seismol. Soc. Japan, 2010.

Ruangrassamee, A., Yanagisawa, H., Foytong, P., Lukkunaprasit, P., Koshimura, S., and Imamura, F.: Investigation of TsunamiInduced Damage and Fragility of buildings in Thailand after the December 2004 Indian Ocean Tsunami, Earthq. Spectra, 22, 377-401, 2006.

Suppasri, A., Koshimura, S., and Imamura, F.: Developing tsunami fragility curves based on the satellite remote sensing and the numerical modeling of the 2004 Indian Ocean tsunami in Thailand, Nat. Hazards Earth Syst. Sci., 11, 173-189, doi:10.5194/nhess11-173-2011, 2011. 
Suppasri, A., Koshimura, S., Matsuoka, M., Gokon, H., and Kamthonkiat, D.: Remote Sensing: Application of remote sensing for tsunami disaster, in: Remote Sens. Planet Earth, edited by: Chemin, Y., 143-168, InTech, 2012a.

Suppasri, A., Mas, E., Koshimura, S., Imai, K., Harada, K., and Imamura, F.: Developing Tsunami Fragility Curves From the Surveyed Data of the 2011 Great East Japan Tsunami in Sendai and Ishinomaki Plains, Coastal Eng. J., 54, 1-16, doi:10.1142/S0578563412500088, 2012b.
Yamazaki, F., Maruyama, Y., Miura, H., Matsuzaki, S., and Estrada, M.: Development of Spatial Information Database of Building Damage and Tsunami Inundation Areas following the 2010 Chile Earthquake, Tech. rep., 2010 Chile Earthquake and Tsunami Technical Report - JST-JICA SATREPS Peru Project, http://ares.tu.chiba-u.jp/peru/pdf/output/tr/ JST-JICA-CHILE-EARTHQUAKE-AND-TSUNAMI-REPORT. pdf, 2010. 